Review

\title{
Pieter Pauw (1564-1617)
}

\author{
Sergey A. Kutia, Leylia R. Shaymardanova
}

V.I. Vernadsky Crimean Federal University, Simferopol, Russia

Received 21 May 2017, Accepted 19 June 2017

(C) 2017, Kutia S.A., Shaymardanova L.R.

(C) 2017, Russian Open Medical Journal

Abstract: This article describes life and works of Dutch anatomist and botanist Pieter Pauw (1564-1617). Special attention paid to anatomical theatre at Leiden University established by him in 1597 and foundation of famous anatomical school. His contribution to clinical medicine (first documented description of diabetes insipidus and retinoblastoma), anatomy (discovery of maxillary sinus, "ossiculus Pavonius") and botany (development of botanical garden) is described.

Keywords: history of medicine, Pieter Pauw, anatomical theatre, botanical garden

Cite as Kutia SA, Shaymardanova LR. Pieter Pauw (1564-1617). Russian Open Medical Journal 2017; 6: e0309.

Correspondence to Prof. Sergey A. Kutia. Address: Medical Biology Department, Medical academy named after S.I. Georgievsky of V.I. Vernadsky Crimean Federal University, 5/7, Lenina boulevard, Simferopol, 295051, Russia. Phone: +7(3652)554-714. E-mail: sergei_kutya@mail.ru.

This year we remember the 400 years anniversary of the death of the prominent and outstanding scientist, anatomist, botanist and medical doctor Pieter Pauw (Figure 1), whose contributions were so valuable that promoted the further upsurge of many different fields of sciences for the Renaissance period.

The available preserved sources about his activities show different transliteration of his name: Peter Pauw, Pieter Paaw, Peter Peacock, Petrus Pavonius, Petrus Pauwius.

Pieter Pauw (Petrus Pavius in Latin interpreting), was the representative of the European science school of the XVI century, and became famous for his anatomical theatre in Leiden.

He was born in Amsterdam in 1564 in the noble family of Pieter Pauw Adriaanszoon, the member of the city council, at the same time he was a nephew of the powerful Amsterdam regent Reinier Pauw. From his mother side, his uncle was Hendrick Laurensz Spieghel, the Dutch poet and philosopher, who shared the ideas of humanism in Dutch society. The private correspondence between him and Pieter showed how close they were in their world perception from the philosophical point of view.

In 1579 seven northern Dutch territories named United Provinces became independent from the Catholic south, and very soon they became recognized for the intellectual and finance freedom and potential. The Leiden University acquired the leading positions in many fields of sciences in Europe. There Pieter Pauw obtained his education on the faculty of arts from 1581 to 1584 . Among his great teachers were professor of medicine Jan van Heurne (1543-1601), professor of medicine, mathematics and astronomy Geraert de Bondt (1536-1599), professor of medicine Rembert Dodoens (1517-1585), who was the former court physician of the King of Spain Philip II and then of the Holy Roman Emperor Rudolf II. Probably, their influence inspired the young man to think more about medicine.

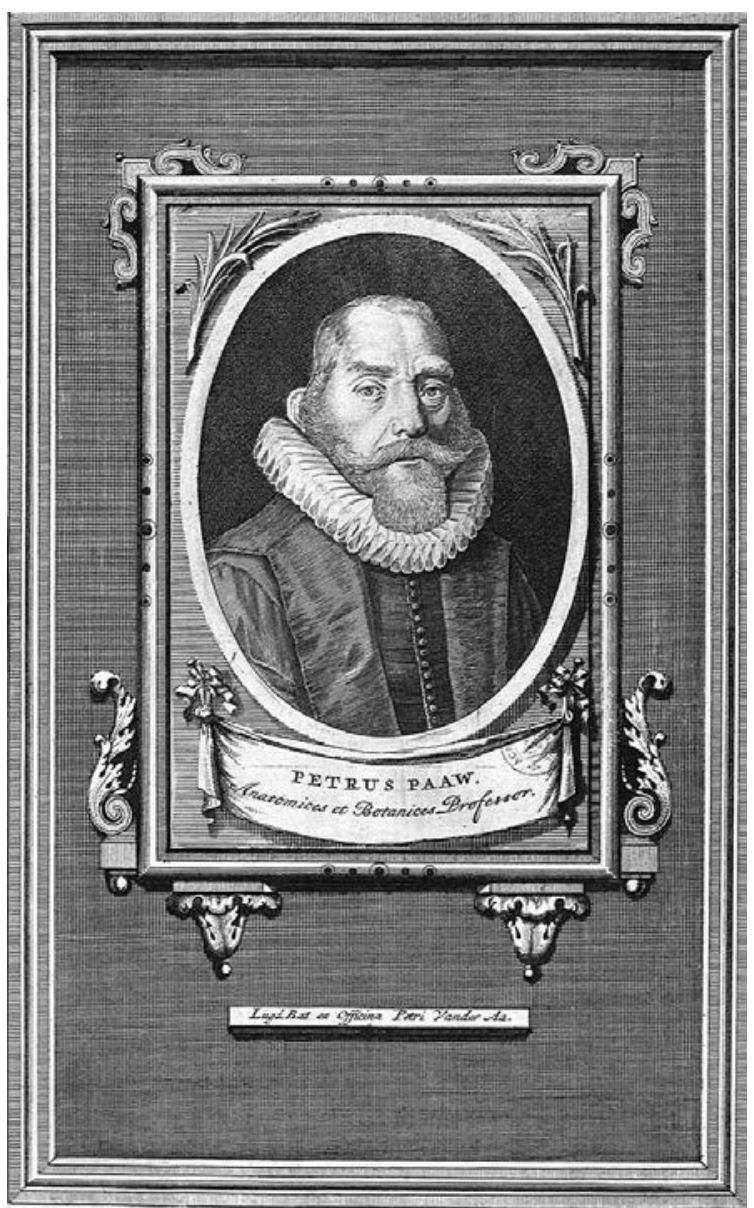

Figure 1. Pieter Pauw (1564-1617) 


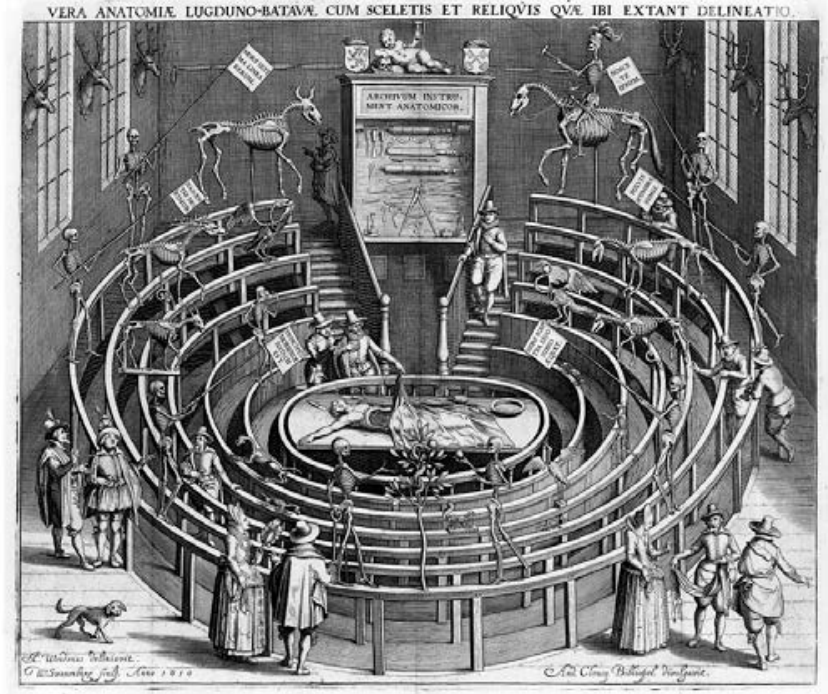

Figure 2. View of the Leiden anatomical theatre, engraved by Willem Swanenburg, drawn by Jan van Woudt

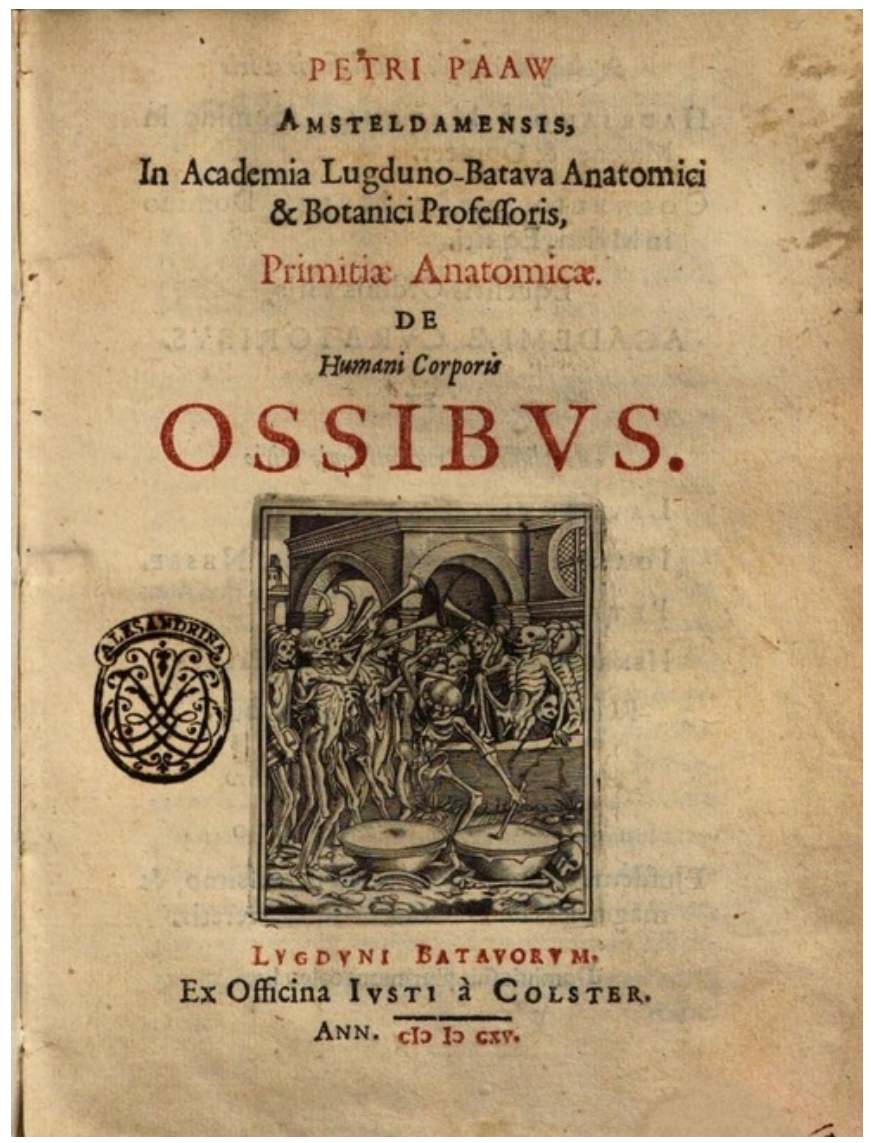

Figure 3. Title page of Pauw's "Primitiae anatomicae de humani corporis ossibus"

After the graduation from Leiden University he travelled abroad for more experience, and continued his education in France, Italy and Germany [1]. In Paris, in the College de France he finally directed his studies towards medicine and was taught by the court doctor of the King of France Charles IX and Henry III professor of medicine Louis Duret (1527-1586) and his son, also professor of medicine Jean Duret (1563-1629).

Later, Pauw attended the courses in the University of Orleans, took classes of Heinrich van den Brock (1530-1593), the professor of mathematics, medicine and astronomy, who was the provost of Rostock University. Under his leadership, Pauw got in 1587 his doctorate in medicine [1]. Then, he moved to Padua (Italy). Padua University was attractive for many scientists for its tolerance, especially from a religious point of view, in the time of inquisition. There he was taught by Girolamo Fabrizi d'Acquapendente (1537$1619)$, the prominent professor of surgery and anatomy, also known in medical science as "The Father of Embryology". Also, there he got acquainted with Giulio Casserio (ca. 1545-1616), the author of "Tabulae anatomicae", one of the most important treatises of that time, which opened a new epoch in anatomical illustration. During his stay in Padua Pauw gained the comprehensive knowledge about the university medical garden and the appropriate place for anatomy classes. That influenced his preferences in future. The solid background described above couldn't but create the bright professional with an incredible experience and progressive ideas.

In 1589 the news about his father serious disease forced Pauw to go back to United Provinces. In Leiden Academy he was proposed full professorship of anatomy and botany (first in University history), serving in that position until his death in 1617, one day before his 53-d birthday.

In 1593 Pieter Pauw married Maria van Hout, a daughter of Jan van Hout, who was the former city and University secretary, but mainly poet and playwright. The couple had seven children, two of them died in childhood.

His anatomical contribution included, but was not limited by, the foundation in 1597 the amazing anatomical theatre for dissection (Figure 2) [2]. It was the second permanent one to be built in the world, after Paduan Fabrizi's theatre. Pauw designed it as six ascending rows of seats that were interrupted by spaces for passage and encircled the scene in the middle. In the anatomical theatre the first two rows were reserved for professors and nobility, two more rows were occupied by students and barbersurgeons, and two upper rows were for visitors who had to pay an entrance fee of fifteen pence.

There the table for dissection and the cupboard for the instruments were established. The large windows let the daylight in during dissections, and when they were over, the premise became a museum. The human and animal skeletons, which were quite unusual for that time, were demonstrated to the visitors. On the walls the anatomical prints of Vesalius works, engravings of Jan Cornelisz Woudanus, opposite to entrance - male's and female's skeletons, hinting at Adam and Eve, who lost their immortality for their sins. Adam was shown with a spade and Eve with a snake and forbidden fruit. Philosophical ideas were present in most of pictures; they served the emblems of Vanitas, the fragility of the human life.

Later the same type anatomical theatres were copied by many Universities.

Pieter Pauw's enthusiasm and talent was so evident, that he could claim for a personal assistant with the fixed salary for fetching peat, making fire, heating water, preserving the corpse for dissection and et cetera. Pauw also applied for funds to buy the sets of instruments and vessels for anatomical needs, 40 plates after Vesalius for the anatomical theatre, and later even to 
construct a shed for assembling the skeletons from the animal's remains.

Pauw also asked the Curators of the University to urge the States of Holland and West Vriesland to enforce their resolution of 1593, ordering the tribunals of the Holland cities to deliver their executed criminals to the Leiden anatomical theatre in winter time [1].

He got the legal right to dissect the executed criminals on public. These dissections attracted much attention and were not only visited by students, but also by non-students. Before a new dissection a bell announced the beginning of anatomical demonstration. Each dissection was reported to last three days. After the dissections he made the autopsy notes.

For about nineteen years Pieter Pauw dissected more than sixty cadavers, including of children. Pauw dissected not only human corpses, but calfs too. Also he provided the theater with a collection of unique objects, including congenital malformations. He described his observations in autopsy reports.

Among them was the earliest known case of the diabetes insipidus caused by the cystic tumor, compressing the optic chiasm [3]. Another interesting case, reported was the eye tumor, was included as the "undoubted retinoblastoma" to several academical encyclopedias and manuals on ophthalmology [4].

In 1615, Pieter Paaw was the first to describe the sesameshaped fourth ossicle in the middle ear of oxen within the stapes tendon, sometimes related as the "oval ossicle" [5]. Soon after his initial description, other anatomists began to write regarding this sesamoid bone in both humans and nonhuman mammals, although it does not exist in humans. Descriptions of this additional ossicle in the stapes tendon have been misinterpreted by authors, confusing its terminology. Also it was referred as "ossiculum Pavius".

Paaw re-issued and added his own annotations to the necessary for that time handbook for medical students "De humani corporis fabrica libri septem" by Andreas Vesalius. His notes contributed for clarifying of many issues.

The interesting sketches were revealed in his anatomical masterpiece "Primitiae anatomicae de humani corporis ossibus", published in 1615 (Figure 3).

Besides the detailed description of the bones of the body, including the bones of hand and foot, the pictures with sections of the frontal, maxillary and sphenoid bones show that he was familiar with the presence of paranasal sinuses, including maxillary one, discovery attributed erroneously to British surgeon anatomist Nathaniel Highmore (1613-1685), who described it 36 years after Pauw.

The certain contribution was made by Pieter Pauw to Botany.

In the Renaissance period it was quite common that the medical students were taught the herbs necessary for healing. Therefore in 1590 the mayor of Leiden gave the permission to create a botanical garden behind the University building.

To develop the nice garden that became soon a proud of the Leiden University, three persons were appointed almost at once: Carolus Clusius, Dirk Outgaertsz Cluyt and Pieter Pauw. The famous botanist Carolus Clusius (1526-1609) became a prefect. He arrived in winter in 1593. He was not teaching students or was working in the garden because of his elderly age, but spent most of his time in research and publishing books.

Dirk Outgaertsz Cluyt, the other person in the garden, was the pharmacist. He came to University in 1594 and brought the plants from his private garden in Delft. His responsibilities included the practical needs of the garden.

Before his arrival to University, Carolus Clusius sent seeds to Pieter Pauw for planting. As the seeds of foreign plants were mostly unknown in Europe, the single idea that came to Pauw was to arrange the plants in the garden in the alphabetical order. That way was criticized, but anyway the garden was under the Pauw's care, all the plants had the labels, and in 1601 he published the first botanical catalogue, which was re-edited in 1603, 1617, 1629 [6]. In time, the garden of Leiden became famous. For more than four centuries and till now the rich collection of plants serve for research, education, and exhibition purposes; the wonderful landscapes accept many wedding ceremonies.

The blooming plants made Pieter Pauw busy with the garden within three seasons, while the cold winter months were devoted to the anatomical theatre and dissections. Hence, all year round he was teaching, treating the new talented students, sharing to his best - the knowledge and experience.

The activity of Pieter Pauw promoted the development of the Leiden Anatomical school, that acquired the leading role in Europe in the second half of XVII - XVIII century, and granted to the world such greate scientists as Nicolaes Tulp (1593-1674), François Du Bois (Franciscus Sylvius, 1614-1672), Regnier de Graaf (16411673), Theodor Kerckring (1638-1693), Jan Swammerdam (16371680), Niels Stensen (Nicolas Stenon, 1638-1686), Frederik Ruysch (1638-1731), Adam Christian Thebesius (1686-1732), Lorenz Heister (1683-1758), Bernhard Siegfried Albinus (1697-1770), Alexander Monro I (1697-1767), Albrecht von Haller (1708-1777), Peter Camper (1722-1789).

Conflict of interest: none declared.

\section{References}

1. Huisman T. The finger of God: anatomical practice in 17 th century Leiden. Leiden, Netherlands, 2008; 202 p.

2. Brockbank W. Old anatomical theaters and what took place therein. Med Hist 1968; 12(4): 371-384. https://doi.org/10.1017/S0025727300013648.

3. Kivela T, Polkunen M-L, Oja M, Heiskanen O. Diabetes insipidus and blindness caused by a suprasellar tumor: Pieter Pauw's observations from the 16th century. JAMA 1998; 279(1): 48-50. https://doi:10.1001/jama.279.1.48.

4. Kivela T, Polkunen M-L. Pieter Pauw's tumor oculorum: reappraisal of the presumed first description of retinoblastoma in 1597. Arch Ophthalmol 2003; 121(6): 881-886. https://10.1001/archopht.121.6.881.

5. Graboyes EM, Chole RA, Hullar TE. The ossicle of Paaw. Otol Neurotol 2011; 32(7): 1185-1188. https://10.1097/MAO.0b013e31822a28df

6. Conan M. Baroque garden cultures: emulation, sublimation, subversion. Washington, USA, 2005; $433 \mathrm{p}$.

\section{Authors:}

Sergey A. Kutia - MD, DSc, Professor, Head of Medical Biology Department, Medical academy n.a. S.I. Georgievsky, V.I. Vernadsky Crimean Federal University, Simferopol, Russia. http://orcid.org/00000002-1145-4644

Leylia R. Shaymardanova - MD, PhD, Associate Professor, Human Anatomy Department, Medical academy n.a. S.I. Georgievsky, V.I. Vernadsky Crimean Federal University, Simferopol, Russia. http://orcid.org/0000-0003-3154-3203. 